\title{
Candide and Botanical Software: technology cultivating garden visitation and collection management
}

\author{
Waheed Arshad', Havard Ostgaard ${ }^{2}$, Mats Havström³ ${ }^{3}$ Jo Elworthy ${ }^{4}$, Jon Hall ${ }^{5}$, \\ Keenan Simons ${ }^{6}$ \& Helen Allsebrook ${ }^{7}$
}

\begin{abstract}
Botanic gardens and related institutions are positioned as centres of expertise in plant biodiversity and conservation. Together with its collection policy and overall mission, the structured documentation of a garden's collection of plant material characterises an institution as a botanic garden. However, the currently available tools and processes are not cost-effective or accessible at a global level, nor do they provide the necessary efficiency for the needs and workflows of botanic gardens and plant collection management. In the context of visitation of these gardens, there is also a well-established disconnection between people and plants that many institutions have previously attempted to address through engaging interpretation.

Several innovative initiatives towards tackling these challenges are presented here. The paper explains Candide's application of machine learning in the automatic identification of plants and digital engagement through smartphones to aid visitor experience (including tools such as augmented reality). It goes on to explore the documentation of quality plant records data for collections, and how advancements in Botanical Software's new collection management system can play a major role in the efforts of the botanic garden community. The ongoing developments in technology available to botanic garden staff and their visitors present positive contributions towards both tackling global challenges associated with plant conservation and engaging diverse audiences in the fascinating kingdom of plants.
\end{abstract}

\section{Introduction}

Humans are innately attracted to nature, its biodiversity and the appearance of the natural world (Wilson, 1984). However, to many people, plants are invisible or inaccessible through a lack of environmental awareness ('nature-deficit disorder') (Louv, 2008). Coupled with this are accusations

\footnotetext{
${ }^{1}$ Waheed Arshad is Botanical Scientist at Botanical Software Ltd (a subsidiary of Candide Ltd). Address: 40 Queen Square, Bristol, BS1 4QP, UK.

Email: waheed@botanicalsoftware.com

${ }^{2}$ Havard Ostgaard is CEO at Botanical Software Ltd.

Address: as above.

${ }^{3}$ Mats Havström is Director of Collections and Research at Gothenburg Botanical Garden. Address: Carl Skottsbergs Gata 22A, S-413 19 Göteborg, Sweden.

${ }^{4}$ Jo Elworthy is Director of Interpretation at the Eden Project. Address: Bodelva, Cornwall, PL24 2SG, UK.

${ }^{5}$ Jon Hall is Software Engineer at Candide Ltd.

Address: 40 Queen Square, Bristol, BS1 4QP, UK.

${ }^{6}$ Keenan Simons is Software Engineer at Candide Ltd.

Address: as above.

${ }^{7}$ Helen Allsebrook is PR, Media and Communications Lead at Candide Ltd.

Address: as above.
} 
of zoo-chauvinism, which propagates the anthropocentric ranking of plants as inferior to animals, and the concept of 'plant blindness' which has been defined as the inability to recognise plants in the biosphere (Hoekstra, 2000; Wandersee \& Schussler, 1999). Today, two in five plant species are estimated to be threatened with extinction globally (Antonelli et al., 2020). Addressing these threats is crucial in the face of an unprecedented biodiversity crisis in which the efforts of botanic gardens play a pivotal role. In view of these significant challenges, adopting new approaches to managing plant records, communicating the value of gardens' uniquely rich collections and connecting people with plants in the digital era all bring exciting opportunities to reach, and engage with, a much wider audience.

\section{Candide: a technology ecosystem for plants and gardens}

In the satirical tale Candide, ou l'Optimisme, the enlightened playwright François-Marie Arouet (1694-1778), known by his nom de plume Voltaire, concluded with the thought: 'Let us cultivate our garden'. This was a suggested solution to deal with the contrast between the violence and plunder of kings, and the peaceful life of those who minded their own business (Voltaire, 1759). Though gardening has been associated with therapeutic benefits since the 1800s (Clatworthy et al., 2013), recent research has acknowledged the importance of gardens and plants for physical, mental and social wellbeing (e.g. Hall \& Knuth, 2019; Keniger et al., 2013; Vujcic et al., 2017). Cultivating this connection forms an integral part of Candide Ltd, a software company based in Bristol (UK), which provides digital solutions for professional and consumer gardening audiences. Alongside making plant care information more accessible, Candide's mission has evolved into becoming a central marketplace for selling plants, and providing digital ticketing services for public garden visitation. ${ }^{8}$ This provides gardens with improved oversight of visitor footfall, reduces waste and enables safer capacity management. In contrast, Botanical Software, a subsidiary of Candide Ltd, is developing a new platform for the management of plant collections in private and professional gardens. ${ }^{9}$ In this paper, we discuss some of the current challenges to garden visitation, interpretation and collection management, and the role technology plays in their solutions.

\section{Curation and cultivation in the 21st century: a digital approach}

\section{Automated plant identification through artificial intelligence}

One of the solutions developed at Candide involves assisting the general public with plant identification. Accurate plant identification is valuable not only for scientific workflows and in plant conservation (Wäldchen \& Mäder, 2018), but across other levels of botanical and horticultural expertise too. For novice botanists and amateur plant enthusiasts in particular, the challenges of plant identification via morphological characters and key-based approaches have been made more convenient by automated methods using photographs (Wäldchen et al., 2018). Together with rapid advancements in the field of computer vision and machine learning, these workflows have allowed for more user-friendly solutions to plant

\footnotetext{
${ }^{8} \mathrm{https}: / /$ candidegardening.com

${ }^{9}$ https://hortis.com/
} 
identification. The field, more broadly referred to as artificial intelligence (Al), is among the fastest growing in computer science and is seeing more applicability in botany and plant science (e.g. Ma et al., 2014; Mahood et al., 2020; Singh et al., 2016).

From a machine learning perspective, automated plant identification from imagery (i.e. from a mobile device's built-in camera system) is known as a supervised classification problem. This typically requires a training phase (Fig. 1a), using an extensive library of digital imagery that has been independently and accurately identified. The 'training' and 'validation' images determine the parameters of the identification model, which are modified to provide the maximum discrimination between trained taxa. The 'test'

a

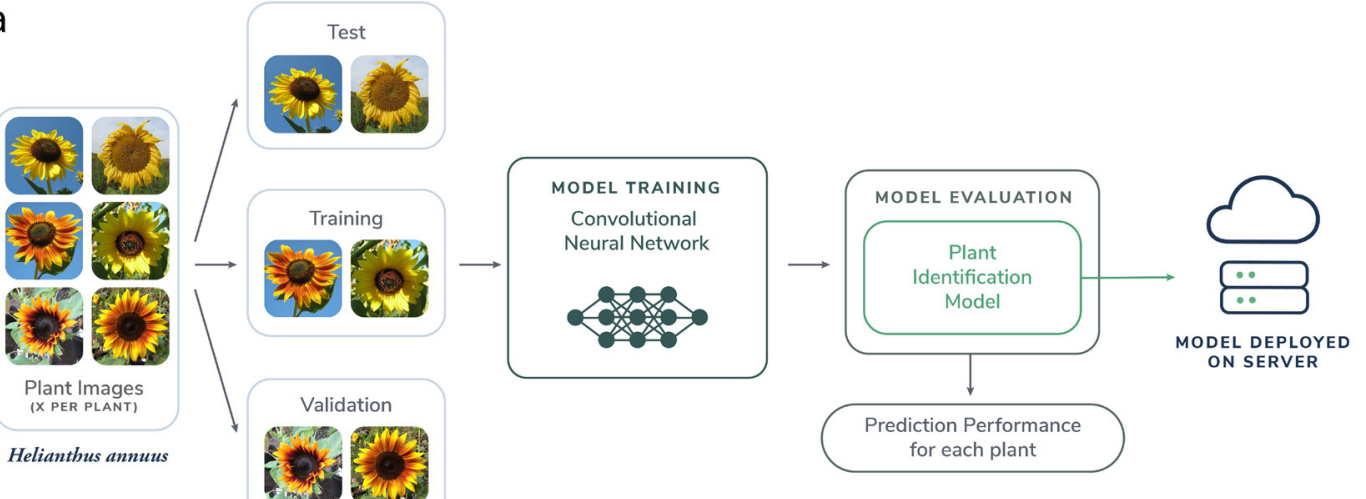

b

INPUT

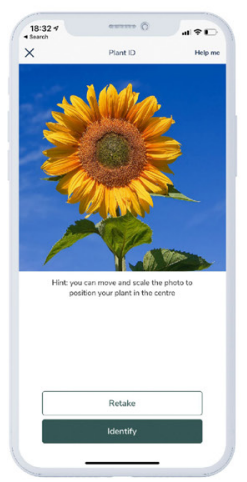

Plant Identification Model

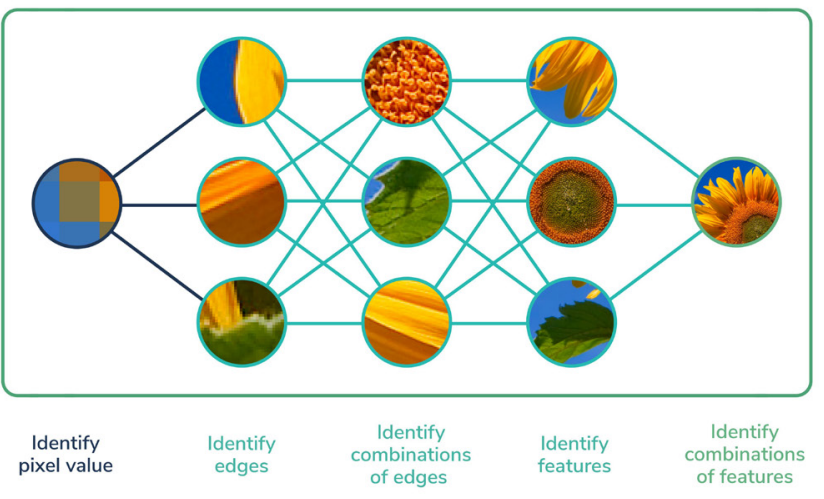

OUTPUT

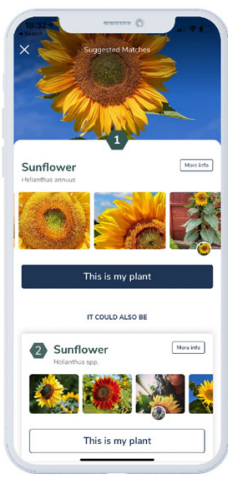

Fig. 1 Application of machine learning in Candide's automatic plant identification tool. (a) Prior to the model being trained, three types of imagery are required per plant. A library of accurately identified 'training' imagery is used to fit the model. The 'validation' imagery is used to provide an unbiased validation of a model (based on the training dataset), while the 'test' data provides a standard used to evaluate the model once it has been trained. Once the performance has been verified, the model is made available on a server for use on mobile devices. All Helianthus annuus (common sunflower) images CCO 1.0. (b) Schematic representation of how a convolutional neural network is utilised within the model. This is a network of nodes, analogous to neurons, that allows information from the image (input) to be processed for the identification (output). By adjusting the weight each link carries within the trained model, the 'learning' can be improved. Input image H. annuus by Fir0002/Flagstaffotos (CC BY-NC 3.0). Definitions: edges = pixels that exhibit rapid intensity changes from their neighbours; features = other regions with certain properties. 
data evaluate those end results. For the best performance, images within the model must convey a reasonable breadth of variation in key characteristics, such as development stage (e.g. young vs mature plant) and reproductive organs (e.g. flower vs fruit), as well as smaller intraspecific characters (e.g. closed and open flower states), some of which may not always be readily or accurately captured in a photograph.

When the trained model is exposed to a new image of an unidentified plant, the image is assigned according to 'edge' and 'feature' detection (Fig. 1b), and presented as a convenient list of candidates to the user. The identification therefore requires minimal effort and little expert knowledge on the part of the user, particularly when the tool is implemented as a mobile app. The user's identified image(s) can then be further utilised as part of the 'training' set, enhancing the image dataset for that taxon. In addition to users' images, there are large numbers of digital image repositories available online (e.g. iNaturalist and Zooniverse). ${ }^{10}$ The Global Biodiversity Information Facility (GBIF), an international network aggregating biodiversity data, is also an important infrastructure supporting data accessibility at the global level (GBIF Secretariat, 2019). These large, crowdsourced image datasets, with the latest advances in machine learning, enable image-based species identification to become increasingly powerful, yet accessible to a range of audiences. For serious botanical and ecological surveys, however, Al-based identification may not be suitable or have the desired accuracy. Images may also require an additional level of moderation, particularly when used for training data. Despite this,

${ }^{10}$ www.inaturalist.org and www.zooniverse.org respectively. mobile apps primarily for identification are often well suited to beginners and amateurs; such tools also provide a user-friendly approach to stimulating greater interest in plant identification, particularly when combined with accessible plant care information.

\section{Case study: using smartphones to enhance visitor experiences at the Eden Project}

Although there has been an explosion in the availability of apps and smartphone technology to aid plant identification (Jones, 2020a, 2020b), few have permitted a holistic approach to plant identification, storytelling and accessible plant information. Particularly in the context of botanic garden visitation, Candide is uniquely positioned to offer this capability. It is estimated by Botanic Gardens Conservation International (BGCI) that visits to botanic gardens and arboreta internationally number $\sim 300$ million per year (Ballantyne et al., 2008; Williams et al., 2015). Garden collections offer botanical havens for study and, together with staff expertise, can be used to encourage deeper links between plants, habitats and our everyday lives. Furthermore, botany and plant sciences are in decline at all levels of the education hierarchy, requiring new approaches to inspire and engage a future generation of plant enthusiasts (Hoekstra, 2000; Thorogood, 2020). Botanic gardens therefore present numerous educational and visitor engagement opportunities for people of all ages, backgrounds and abilities.

Inspiring people's passion for plants, revealing the interconnections between plants and people, and creating a pro-sustainability learning environment are among the key missions of the Eden 
Project. Established in 2000 in Bodelva, Cornwall (UK), this educational charity and major tourist attraction aims to connect people to the natural world through its two iconic interrelated clusters of modified geodesic conservatories, called Biomes, and contemporary Outdoor Gardens. The Eden Project is now also developing a number of projects internationally. Central to its evolving education, interpretation and communication strategies are plant stories that engage the visitor by weaving human narratives around them: tales of adventure, emotion and derring-do. Learning environments and advancements in communication and information technology are continually changing, and digital storytelling is rapidly becoming a key approach to 21 st-century learning (Niemi \& Multisilta, 2016).

With the need to attract the broadest and most diverse audiences, the use of technology can support novel methods of engagement not previously applied to plants and garden visitation. Together with Candide, this collaboration has involved a multisensory approach, combining audiovisual cues via smartphone technology (Figs 2a, $2 b)$. Free-to-use, immersive audio tours have spotlighted the plant collections, cultural history and landscape design of gardens through the voices of expert horticulturists and garden staff. This self-guided and personalised digital tour guide, alongside in-depth visitor interpretation, has enabled gardens like the Eden Project to engage visitors using different content types. Another key advantage of allowing the 'visual to be made verbal' is that audio tours can be offered in many formats and applications, and can be focused on specific target groups such as children. When combined with directional information, they can enable visitors who are visually impaired to become more immersed in gardens. Together with multilingual options for international audiences, these options open up a wealth of outreach opportunities for botanic garden visitation on an international level.

The second layer of this digitally enhanced experience addresses the challenge visitor-focused gardens have in whether or not to display plant labels on all specimens (Fig. 2c). Though plant labels are vital to the curation of garden collections, they may pose a number of logistical and aesthetic challenges, particularly in naturalistic planting schemes. To alleviate this issue, the use of automatic plant identification via visitors' own smartphones allows people to photograph plants, access identifications in seconds and consume plant information at their own discretion. From the ethnobotanical tales of Pandanus tectorius (screw pine), to the therapeutic properties of dried Areca catechu (betel palm) fruits, Candide has been able to promote several stories for visitors. Therefore, in addition to being self-guided, the use of an Al-based tool increases opportunities for more creative interpretation, and 'calls to action' - marketing prompts for immediate responses - for specific plants or groups of plants.

Technology-assisted potential for learning and interpretation in systematic gardens

The application of technology in creative interpretation has potential in other domains within a garden. Since Linnaean times, many botanic gardens have maintained a systematic garden - a section where a number of plants are arranged according to their systematic relations to each other. These sometimes elaborately shaped 'order beds' are used as a compact synopsis of 


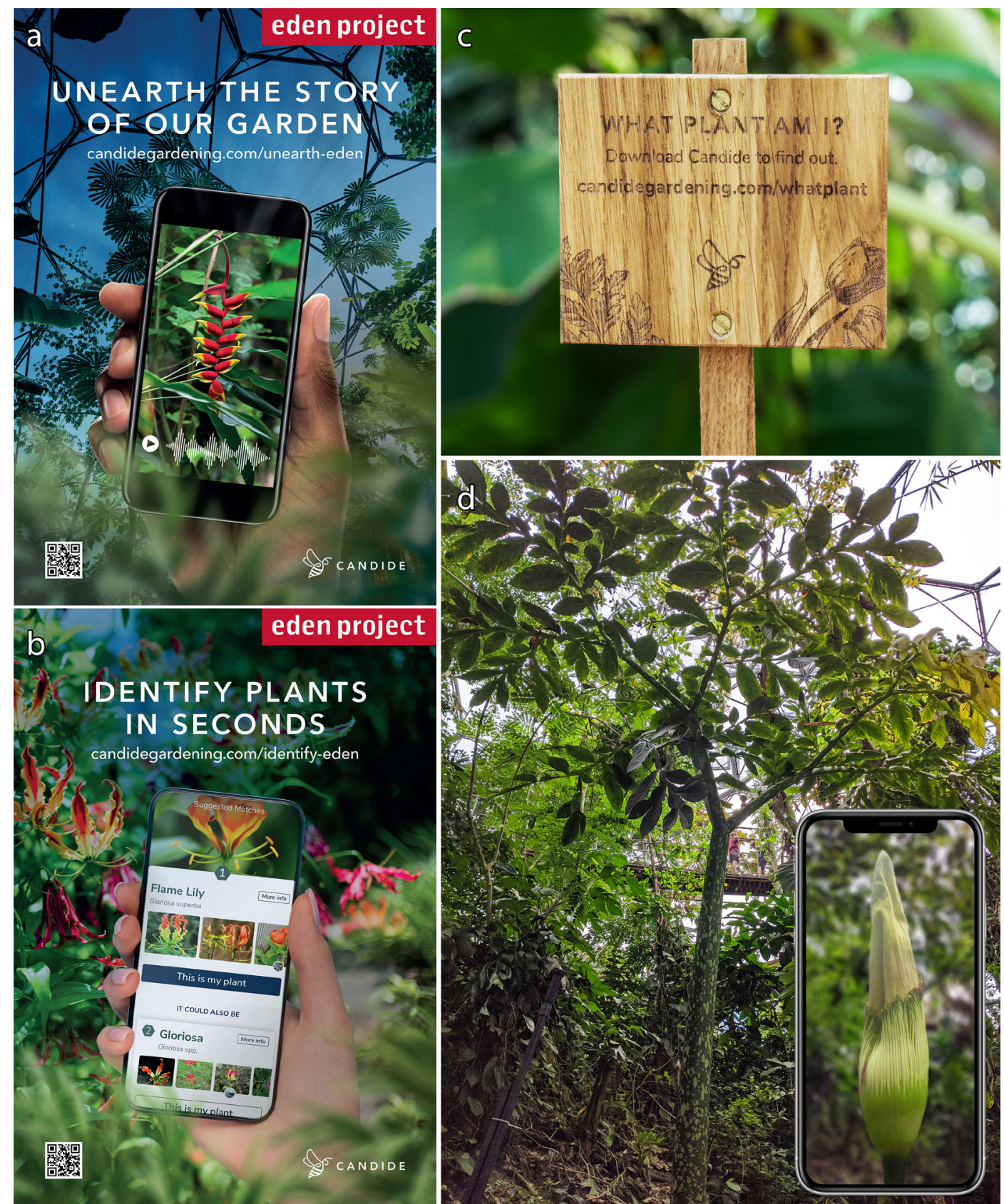

Fig. 2 Gardens such as the Eden Project play a key role in increasing public awareness about global challenges, and present numerous engagement and educational opportunities. The use of Candide's immersive audio tour (a) and automatic plant identification tool (b) has enabled the garden to highlight specific plants in its collection, showcase ethnobotanical stories to visitors and trial new advancements in communication and visitor experiences such as (c) plant labelling and augmented reality (AR). For example, depicting the flowering state of Amorphophallus titanum (titan arum; inset) overlaid on the vegetative state (d) is one botanical story where AR technology could be successfully applied. This endangered species flowers rarely in cultivation, but is a proven example of a biologically interesting and charismatic plant that excites the wider public. Flowering A. titanum image modified from Andy Roberts (CC BY 2.0; flic.kr/p/nwLUX6). 
the plant kingdom arranged in taxonomic sequence, and provide learning opportunities to compare characters that are crucial for the determination of each taxonomic grouping. However, this comes with many practical constraints.

The most obvious constraint of a systematic garden is that only living representatives can be displayed. This led Dahlgren (1989) to the construction of a two-dimensional image (dahlgrenogram) of plant kinship, representing a crosssection of an imagined three-dimensional evolutionary tree, which can be used to construct a systematic garden. A second problem is that the idea about how plants are related changes as the science of taxonomy progresses. The third problem relates to keeping related plants with different life forms or from different climates in the same flower bed. Some taxa cannot thrive in the same microclimate so, for the gardener, it may be painstaking work to keep large numbers of plants at their best at the same time. Furthermore, the composition may not look satisfactory, and the cost of maintenance may be high.

Although the above may deter anyone with a desire to create a systematic garden, the most important obstacle is that many interesting plant groups are not likely to be represented at all in a series of regular flower beds. They may be too large (e.g. conifers, division Pinophyta) or too small (e.g. non-vascular land plants), have too specific climate requirements (e.g. Welwitschia and Cycas spp.) or be too valuable (Amborella, orchids, etc.). This means that many botanic gardens in Europe almost exclusively display herbaceous flowering plants from cold climates in their systematic gardens - an incomplete representation of the diversity of the plant kingdom.
With limited practical solutions to these issues, one technology-assisted approach being explored by Candide is to complement existing planting schemes with devices that act as touchpoints to access further information. This could occur in a number of immersive, digitally entertaining and engaging ways. Among the suitable technologies is augmented reality (AR), which has already been employed in botanical learning experiences in primary schools (Chien et al., 2019). Mobile AR systems have also been used in electronic field guides and techniques for in-field virtual vouchers (White et al., 2006). AR requires higher-end compatible devices, and involves the perception of digital overlays (graphics, text or animations) in the real-world environment. AR can be further enhanced using virtual reality (VR), which brings users to a fully digital world with 360-degree content via physical headsets, giving them completely immersive digital entertainment and learning opportunities. That way, visitors can be partially (in AR) or fully (in VR) engaged in plants within systematic beds, be it at a visitor centre or a greenhouse dedicated to evolution and systematics. As the content is digital, advances in the field of taxonomy could be readily incorporated, while also including visuals of plant groups that cannot be physically represented.

Though the concept of AR and tourism 'through a virtual lens' is relatively new for horticulture and garden visitation, it is an exciting field being explored by Candide with a number of partner gardens in the UK and Europe. One such candidate is Gothenburg Botanical Garden (Sweden), where education, scientific research and visitation are all closely linked with the plant collection. There has been a positive shift in attitudes towards technology in gardens, and 
both $\mathrm{Al}$ (through plant identification) and AR (through enhanced visitor experiences) are two of many examples that can help diversify audiences, improve digital skills and increase engagement with plant collections. The expectation is that the frequency of visits and peer recommendation will increase when visitors use Candide's technology to improve navigation, listen to stories, identify collections and ultimately lock in lifetime value for the garden.

\section{Challenges and further opportunities}

Facilitating documentation of quality plant records data for botanical collections

Coupled with a botanic garden's collection of plant material and related data is its systematised and structured documentation. In line with its collection policy and overarching mission, this characterises an institution as a botanic garden. Plant records are fundamental for the effective curation and use of the botanic garden's plant holdings, with relevance to research, conservation, history and education. In this section, we discuss the current challenges in plant record keeping, and some of the opportunities that Botanical Software's technology offers in improving workflows for garden staff.

A number of tools are available for accessioning and plant records: from paperbased notebook and index-card approaches to spreadsheets and dedicated collection management systems. However, according to the BGCl's GardenSearch, a database of over 3,712 botanical institutions worldwide, only 707 institutions (19 per cent) have a computerised plant record system. ${ }^{11}$ Though paper- and spreadsheet-based approaches

\footnotetext{
${ }^{11}$ https://tools.bgci.org/garden_search.php
}

represent a cheap entry point for gardens to compile plant records, and an option for institutions where few staff are trained in database management, they limit the workflows of collection holders and garden curators. Particularly for gardens that have many taxa and other plant material data, basic searching and sorting of existing plant records can become an onerous task. It is not difficult to fathom how dedicated systems can vastly improve methods for data collection and storage, in processing data for plant labelling and communicating the value of collections (Gratzfeld, 2016).

The investment involved in purchasing, maintaining and updating a collection record management system requires shortand long-term foresight. However, it is well documented that the advantages of computerised systems generally outweigh the initial expenditure. Many botanical institutions are stretched for resources and are required to make difficult choices on where to focus their efforts. For example, the horticultural work involved in looking after living collections may be prioritised over curatorial work and maintaining quality plant records. This is in part due to the high costs of running and managing software, inadequate data collection workflows, and the poor usability and design of existing systems. Improvements in data collection software are slowly reducing the overall cost of keeping records, as are new ways of capturing data such as radio frequency identification (RFID) and barcodes on plant labels (Havinga \& Ostgaard, 2016). Candide's technologies, such as automatic plant identification and AR, may also have the potential to further increase efficiency with collection management workflows.

To address these fundamental challenges in plant record keeping, Botanical Software 


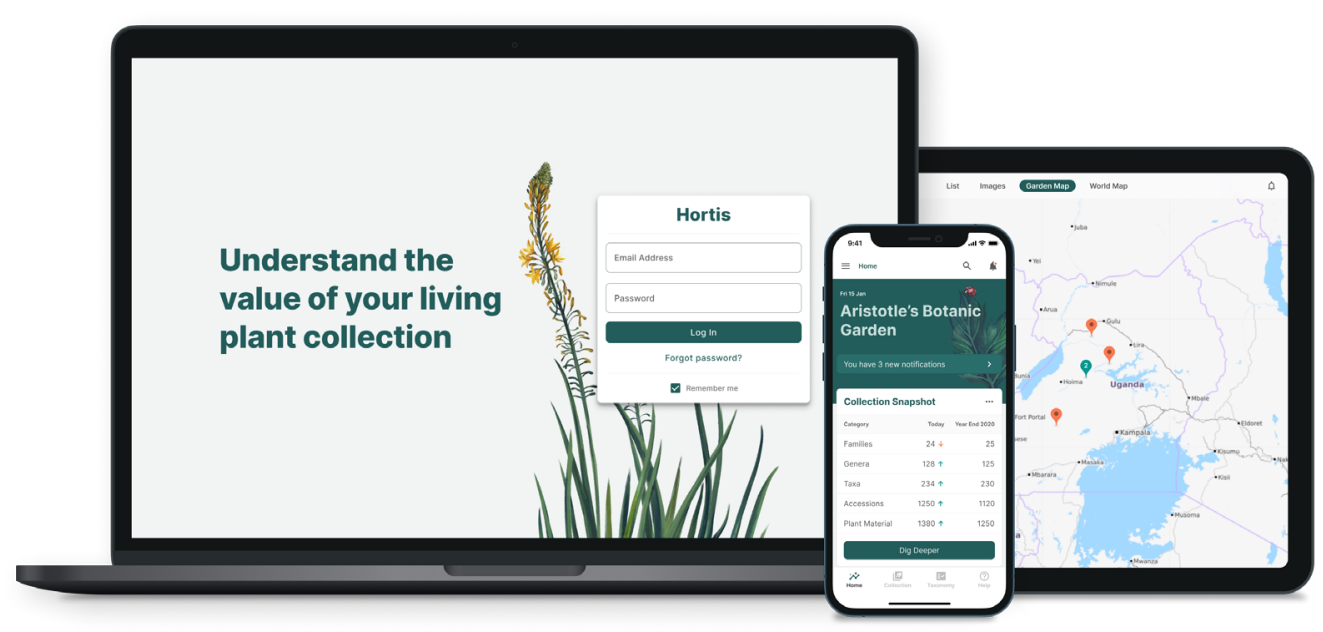

Fig. 3 Hortis (https://hortis.com), Botanical Software's next-generation plant collection management system. From the in-field acquisition of the taxon to basic data analysis of gardens' plant collections, there are a number of processes which will be vastly improved. As devices and training become more widely available and affordable, this platform facilitates a more inclusive and comprehensive approach to plant conservation and the extended roles (including cultural and historical) of botanic gardens. Base map and data from OpenStreetMap and OpenStreetMap Foundation, (c) OpenStreetMap contributors (openstreetmap.org).

is developing Hortis, the next-generation platform for the management of living plant collections (Fig. 3). Existing record-keeping systems are typically desktop-centric and lack the flexibility that a mobile solution offers. Considering the increased digitisation of gardens (discussed above), there is increased demand from curators and horticultural staff for more lightweight tools that have enhanced data-sharing capabilities. Being a cloud-based platform, Hortis will open up new ways for all types of gardens to manage their plant collections. This will also facilitate plant collection holders to work together, regardless of where they are located in the world. It will also allow plant records to become integrated with the diverse missions of gardens; this includes not only gardens active in research, conservation and education, but also historic and cultural institutions, as well as privately owned gardens.

There is also scope for Botanical Software to incorporate more complex mapping as a standard feature, particularly as this provides an effective communication and analysis tool once the basic inventory needs have been met. A good example of how this has evolved is with University of California, Davis Arboretum (UC Davis Arboretum), a $\sim 100$-acre ( 40.5-ha) arboretum that was founded in 1936 to support teaching and research. In 1982, 'cartoon' maps using paper, pen and vellum were generated to depict the locations of plants. However, these maps soon became difficult to update. The first digital maps were created in 1988 using a team of landscape designers, geographycartographers and horticulturists. Since 2003, use of the high-end mapping software Environmental Systems Research Institute (ESRI) ArcGIS ${ }^{12}$ has enabled links with research projects across the university. This has given rise to the Alliance for Public Gardens GIS, a consortium of collection managers

\footnotetext{
${ }^{12}$ https://www.esri.com/en-us/arcgis/
} 
and geographic information system (GIS) professionals, and the development of a standard GIS data model for use by any garden (Rakow \& Lee, 2011). By including mapping features as standard, Botanical Software will therefore reduce the learning curve for adoption in gardens of all sizes and with all levels of experience. In combination with being a mobile, 'always-on' platform, this will attain higher standards and accuracy of plant records data, all within a fruitful collaborative environment.

\section{Conclusions}

It is evident that technology has had, and continues to have, an impact on the ways people engage with plants. With the expertise in plant biodiversity and diverse living collections, global botanic gardens must also lie in the vanguard of efforts to educate the public. The ambitious goal to engage broad and diverse audiences can build on the mass digitisation of natural history collections to incorporate machine-led processes such as automatic plant identification. Candide's solutions for engaging garden visitors have the potential to challenge the ways in which humans perceive plants, and create a future where the real, augmented and virtual worlds graft and grow together.

For botanical institutions, systems that support their collections and accession data are evolving into more powerful, versatile and mobile solutions with Botanical Software. This will address problems of compiling high-quality plant records in gardens that lack computerised databases. It will further enable a wealth of collaborative opportunities involving plant records and collections data. In spite of the biodiversity crisis and ongoing threats of climate change, the technological developments presented in this paper for both garden visitors and garden staff
- therefore offer a positive outlook towards tackling these challenges.

\section{References}

ANTONELLI, A., FRY, C., SMITH, R.J., SIMMONDS, M.S.J., KERSEY, P.J., PRITCHARD, H.W. ET AL. (2020). State of the World's Plants and Fungi 2020. Available online: https://www.kew.org/sites/ default/files/2020-10/State\%20of\%20the\%20 Worlds\%20Plants\%20and\%20Fungi\%202020.pdf (accessed January 2021).

BALLANTYNE, R., PACKER, J. \& HUGHES, K. (2008). Environmental awareness, interests and motives of botanic gardens visitors: implications for interpretive practice. Tourism Management, 29(3): 439-444. doi: https://doi.org/10.1016/j. tourman.2007.05.006

CHIEN, Y.-C., SU, Y.-N., WU, T.-T. \& HUANG, Y.-M. (2019). Enhancing students' botanical learning by using augmented reality. Universal Access in the Information Society, 18(2): 231-241. doi: https://doi. org/10.1007/s10209-017-0590-4

CLATWORTHY, J., HINDS, J. \& CAMIC, P.M.

(2013). Gardening as a mental health intervention: a review. Mental Health Review Journal, 18(4): 214-225. doi: https://doi.org/10.1108/ MHRJ-02-2013-0007

DAHLGREN, G. (1989). An updated angiosperm classification. Botanical Journal of the Linnean Society, 100(3): 197-203. doi: https://doi. org/10.1111/j.1095-8339.1989.tb01717.x

GBIF SECRETARIAT (2019). GBIF Science Review 2019. Available online: https://www.gbif.org/ document/5Lja8XKRwQDwbhxddOWjtm/ gbif-science-review-2019 (accessed January 2021).

GRATZFELD, J. (2016). From Idea to Realisation. Botanic Gardens Conservation International, Richmond.

HALL, C. \& KNUTH, M. (2019). An update of the literature supporting the well-being benefits of plants: a review of the emotional and mental health benefits of plants. Journal of Environmental Horticulture, 37(1): 30-38. doi: https://doi. org/10.24266/0738-2898-37.1.30

HAVINGA, R. \& OSTGAARD, H. (2016). Barcodes are dead, long live barcodes! Improving the 
inventory of living plant collections using optical technology. Sibbaldia, 14: 133-140. doi: https://doi. org/10.24823/Sibbaldia.2016.196

HOEKSTRA, B. (2000). Plant blindness: the ultimate challenge to botanists. The American Biology Teacher, 62(2): 82-83. doi: https://doi. org/10.1662/0002-7685(2000)062[0082:PBTUCT]2 $.0 . \mathrm{CO} ; 2$

JONES, H. (2020a). Artificial intelligence for plant identification on smartphones and tablets. $B S B I$ News, 144: 34-40.

JONES, H. (2020b). What plant is that? Tests of automated image recognition apps for plant identification on plants from the British flora. $A o B$ Plants, 12(6): plaa052. doi: https://doi.org/10.1093/ aobpla/plaa052

KENIGER, L.E., GASTON, K.J., IRVINE, K.N. \& FULLER, R.A. (2013). What are the benefits of interacting with nature? International Journal of Environmental Research and Public Health, 10(3): 913-935. doi: https://doi.org/10.3390/ ijerph10030913

LOUV, R. (2008). Last Child in the Woods. Algonquin Books, Chapel Hill, NC.

MA, C., ZHANG, H.H. \& WANG, X. (2014). Machine learning for Big Data analytics in plants. Trends in Plant Science, 19(12): 798-808. doi: https://doi. org/10.1016/j.tplants.2014.08.004

MAHOOD, E.H., KRUSE, L.H. \& MOGHE, G.D. (2020). Machine learning: a powerful tool for gene function prediction in plants. Applications in Plant Sciences, 8(7): e11376. doi: https://doi.org/10.1002/ aps3.11376

NIEMI, H. \& MULTISILTA, J. (2016). Digital storytelling promoting twenty-first century skills and student engagement. Technology, Pedagogy and Education, 25(4): 451-468. doi: https://doi.org/1 0.1080/1475939X.2015.1074610

RAKOW, D. \& LEE, S. (2011). Public Garden Management. John Wiley \& Sons, Hoboken, NJ.

SINGH, A., GANAPATHYSUBRAMANIAN, B., SINGH, A.K. \& SARKAR, S. (2016). Machine learning for high-throughput stress phenotyping in plants. Trends in Plant Science, 21 (2): 110-124. doi: https://doi.org/10.1016/j.tplants.2015.10.015

THOROGOOD, C. (2020). Astonishing plants. Trends in Plant Science, 25(9): 833-836. doi: https:// doi.org/10.1016/j.tplants.2020.06.007

VOLTAIRE (1759). Candide, ou l'Optimisme. Cramer, Geneva.

VUJCIC, M., TOMICEVIC-DUBLJEVIC, J., GRBIC, M., LECIC-TOSEVSKI, D., VUKOVIC, O. \& TOSKOVIC, O. (2017). Nature based solution for improving mental health and well-being in urban areas. Environmental Research, 158: 385-392. doi: https://doi.org/10.1016/j.envres.2017.06.030

WÄLDCHEN, J. \& MÄDER, P. (2018). Machine learning for image based species identification. Methods in Ecology and Evolution, 9(11): 2216-2225. doi: https://doi. org/10.1111/2041-210X.13075

WÄLDCHEN, J., RZANNY, M., SEELAND, M. \& MÄDER, P. (2018). Automated plant species identification-Trends and future directions. PLOS Computational Biology, 14(4): e1005993. doi: https://doi.org/10.1371/journal.pcbi.1005993

WANDERSEE, J.H. \& SCHUSSLER, E.E. (1999). Preventing plant blindness. The American Biology Teacher, 61(2): 82-86. doi: https://doi. org/10.2307/4450624

WHITE, S., FEINER, S. \& KOPYLEC, J. (2006). Virtual vouchers: Prototyping a mobile augmented reality user interface for botanical species identification. In: Proceedings of the 2006 IEEE Symposium on 3D User Interfaces (3DUI'06), 25-26 March, Alexandria, VA, USA, pp. 119-126. doi: https://doi.org/10.1109/ vr.2006.145

WILLIAMS, S.J., JONES, J.P.G., GIBBONS, J.M. \& CLUBBE, C. (2015). Botanic gardens can positively influence visitors' environmental attitudes.

Biodiversity and Conservation, 24(7): 1609-1620. doi: https://doi.org/10.1007/s10531-015-0879-7

WILSON, E.O. (1984). Biophilia. Harvard University Press, Cambridge, MA. 
